\title{
What factors lead to self disclosure of bulimic women?
}

\author{
Barbara B. Penprase ${ }^{1}$, Deborah B. Fahs ${ }^{2}$, Linda Honan Pellico ${ }^{2}$ \\ 1. School of Nursing, Oakland University, Rochester, MI, USA. 2. School of Nursing, Yale University, New Haven, CT, USA.
}

Correspondence: Barbara Penprase. Address: School of Nursing, Oakland University, Rochester, MI, USA. E-mail: penprase@oakland.edu

Received: August 27, 2013

Accepted: October 21, $2013 \quad$ Online Published: December 31, 2013

DOI : $10.5430 /$ jnep.v4n2p218

URL: http://dx.doi.org/10.5430/jnep.v4n2p218

\section{Abstract}

Bulimia Nervosa (BN) is on the rise in almost every continent. Early identification and treatment is vital to improving health outcomes but recognition of women with bulimia by APNs is suboptimal. A major reason cited in the literature is the lack of disclosure associated with bulimic women. The purpose of this research is to describe factors that led or posed barriers to self-disclosure of BN. A descriptive, qualitative study was used with a convenience sample of fifteen women ages 20-62 who had disclosed their BN. Krippendorff's method was used for content analysis. Factors facilitating disclosure included: possessing a "safety net" related to a relative, friend or HCP; feeling an intrinsic obligation to oneself to disclose; revealing BN as a result of provider "pull" on the patient; yearning to feel well; and relating to someone with a similar experience. Barriers included: shame, embarrassment, guilt and concern related to other's perceptions. Some respondents had not disclosed to a HCP citing exposure might result in feeling forced to stop this behavior. Purging was described as personal and secretive where the seduction of the act itself far outweighed the risks associated with BN. This has important implications for APNs not only in recognizing the reasons underlying disclosure but in understanding how the act itself impacts on earlier detection.

\section{Key words}

Bulimia nervosa, Disclosure, Advanced Practice Registered Nurse (APRN)

\section{Introduction}

Bulimia Nervosa (BN) affects millions of people worldwide and it is among one of the most lethal of psychiatric illnesses affecting individuals of all ages, genders, socioeconomic classes and ethnicities ${ }^{[1-3]}$. BN is a complex disorder involving multiple episodes of over-eating binges followed by self-induced vomiting. It is accompanied by periods of fasting, over exercising, and the use of laxatives, diuretics and/ or enemas; all in a quest to control weight ${ }^{[4]}$.

Lifetime prevalence of BN is estimated to affect $1.5 \%-2 \%$ of women ${ }^{[5]}$. The mortality rate of those with bulimia is 12 times higher than any other disease that afflicts women between the ages of $15-24$ years, and up to $20 \%$ of women impacted with this threatening disorder will die within 10 years of the start of the disorder ${ }^{[5]}$. However, it is strongly believed that because of the stigma and humiliation felt by individuals suffering from BN, these statistics do not accurately reflect the percentage of women afflicted with $\mathrm{BN}$ due to patient non-disclosure ${ }^{[6]}$. 
Non-disclosure of BN negatively impacts health care economics. Statistics reported that eating disorders (ED) cost businesses approximately $\$ 2.5$ billion/year in lost productivity due to absenteeism and poor performance ${ }^{\text {[7] }}$. Just as important, BN negatively affects the physiological, social, and emotional well-being of the individual who suffers from this disorder ${ }^{[8]}$. With the surge of BN identified in almost every continent ${ }^{[9]}$, nurses must become increasingly aware of its existence and its potential life threatening complications ${ }^{[10]}$, some of which include: cardiac arrhythmias, mitral valve prolapse, esophageal rupture, Mallory-Weiss syndrome, pancreatitis, aspiration pneumonitis and cognitive impairment ${ }^{[11]}$.

\section{Literature review}

Evidence supports that very few patients with BN are identified by advanced practitioners, who include health care practitioners (HCPs) and Advanced Nurse Practitioners (ANP), even though their consultation rate with providers, both before and during onset, is substantially high ${ }^{[9]}$. A key reason BN goes unrecognized is due to patients' non-disclosure of symptoms ${ }^{[12]}$. BN is complex in nature and there are a multitude of factors potentially influencing patients' non-disclosure including: denial of the disorder, attempting to appear socially desirable, fearing consequences of self-disclosure and feelings of shame ${ }^{[13,14]}$.

APNs emphasize patient education and disease prevention placing them in an ideal role to perform risk assessment for patients with BN. Moreover, they provide care to large numbers of women and it is within their scope of practice to screen, diagnose, treat, and properly refer women with BN. The secretive nature of this disorder however hinders patient self-disclosure, therefore, delaying diagnosis ${ }^{[11]}$. Though a breadth of studies regarding all eating disorders (ED) have been conducted by physicians, psychologists and behavioral scientists, little research has been conducted by APNs, specifically aimed at factors that led women with BN to self-disclose their disorder ${ }^{[11]}$.

Most research related to self-disclosure cluster individuals with EDs (binge eating disorder, anorexia nervosa and/or BN) under one umbrella. There is a dearth of research on BN; however, investigating factors that led to self-disclosure specifically among bulimic patients is limited. Identifying those factors from the bulimic patient's viewpoint may equip APNs with important information resulting in strategies to help these women self-disclosure and discuss their disorder. While self-disclosure patterns of women with BN have been studied through quantitative methodology ${ }^{\text {[10, 14-19] }}{ }^{\text {, few }}$ studies have focused on the experience of women with BN through qualitative inquiry ${ }^{[20]}$.

BN has been studied in the adolescent and young adult population but there are limited studies aimed at recognizing BN in middle and late life resulting in suboptimal detection in older women. Problem recognition of BN has been linked with greater likelihood of seeking help from a $\mathrm{HCP}^{[18]}$ but older women seldom seek psychiatric services for BN and deny having this disorder even when asked directly by a clinician; posing significant barriers in identification and treatment ${ }^{\text {[21] }}$. While some older women do confide in their advanced practitioner, many remain silent and the disorder is disclosed only by the patient's family ${ }^{[21]}$. Adding to the clinical conundrum, research reveals that even when a patient recognizes a problem, it does not necessarily imply help seeking ${ }^{[16]}$.

The National Institute for Clinical Excellence provides guidelines for advanced practitioners related to management of BN emphasizing the necessity for early screening since identification and treatment impact favorably on health outcomes ${ }^{[22]}$. Research shows that patient self-disclosure is hindered by the fact that advanced practitioners are not questioning patients about BN even though a great majority of these patients have been treated for anxiety or depression ${ }^{[9,12]}$.

Compounding the difficulty of diagnosis is patients suffering from BN may appear with normal weight, thus the advanced practitioners are limited in cues related to body mass index ${ }^{[22]}$. Bulimic women have cited physicians, psychologists, and counselors as valuable resources in discussing their disorder ${ }^{[9]}$; however, other women with BN viewed their consultations with advanced practitioners as poor, if not detrimental in both diagnosis and treatment ${ }^{[20]}$. The complexity of diagnosing 
BN relates not only to issues of patient non-disclosure but to advanced practitioners competency as well as clinician time constraints ${ }^{[9,23]}$. Other reasons may be attributed to lack of knowledge and poor insight into BN both on the part of the patient and the advanced practitioner ${ }^{[9]}$. Individuals with $\mathrm{BN}$; however, may only seek help if they perceive an immediate threat to their own health ${ }^{[24]}$. Additionally, ethnicity and acculturation pose barriers to self-disclosure of BN. In their research on EDs, Becker et al. have suggested that ethnic minority participants were significantly less likely to be asked by advanced practitioners about ED symptomatology ${ }^{[12]}$.

Many bulimic women delay access to the health care system while some never seek help citing shame and feeling stigmatized as major barriers to disclosure ${ }^{[15]}$. Individuals wish to be seen by others as socially desirable and fear being labeled "as having a disorder" ${ }^{[14, \text { p.109] }}$. Failure to disclose has been associated with an inability to view eating behaviors as problematic or the belief that their behaviors "might not be too bad", thereby minimizing the serious nature of $\mathrm{BN}^{[15,25,26]}$.

Reasons for help-seeking included: increase of symptom severity, a desire for improved health, emotional distress, and interference of the disorder with life roles and associated health problems ${ }^{[17]}$. Bulimic women potentially self-disclose to a number of individuals but initially they disclose to a friend ${ }^{[12]}$; very few women first disclose to a family member ${ }^{[18]}$. Less than one-third of women initially disclosed to an advanced practitioner ${ }^{[12]}$ and only $10 \%$ initially disclosed to a psychiatric counselor ${ }^{[18]}$. Women with BN feel misunderstood, distant from others, and lack interpersonal connections leading to extreme feelings of isolation ${ }^{[20,27]}$. Although these women tend to have difficulties disclosing intimate information across all relationships ${ }^{[16]}$ they continue to search for a connection with others ${ }^{[27]}$. Women who disclosed to boyfriends, family members or counselors revered these individuals as their "saving grace" resulting in an awareness of their unhealthy eating behaviors and a return to normal eating patterns ${ }^{\text {[27, p. 103]. }}$

The purpose of this paper was to explore the perceptions of women's experiences as reflected in their comments provided in a survey that sought to gain a better understanding of their experiences with self-disclosure of BN. Insight into their comments can help illuminate how advanced practitioners and policy makers could prioritize efforts to assist this patient population.

\section{Methods}

This was a pilot descriptive qualitative study to identify factors that impact BN self-disclosure among fifteen women using an open-ended survey. This research took place in eight health care settings in southern Connecticut. Two of the settings were primary care private practices; one owned by a nurse practitioner and one by a physician. The remaining six settings were psychiatric private practices; five were owned by nurse practitioners and one by a physician. The sites were chosen due to location and agreement to support this study.

The inclusion criteria were bulimic women over the age of 18 who had disclosed having BN. Demographic information included age which crossed reference inclusion criteria. A convenience sample of fifteen women who were currently seeing an APRN or physician for medical or behavioral reasons consented to participate. They completed an anonymous survey and it was returned by a pre-addressed, stamped envelope mailed to the researcher. Fifteen surveys were collected over a ten-week time frame. Since the surveys were filled out anonymously, the researchers did not know the diagnosis of the participants or why they were seeking treatment from the physician or APRN. A survey developed by the investigators consisted of 11 open-and closed-ended questions; closed-ended questions focused on demographic information while open-ended questions focused on disclosure. The first four questions related to demographic data while the last seven questions were specific to self-disclosure of bulimia. Questions were as follows: How old were you when you first told another person about your bulimia? To whom did you first talk to about your bulimia (friend, relative, health care provider, other) and why this particular person? If you did not initially disclose your bulimia to a health care provider, how long did it take before you sought medical care for your bulimia? During the time you told someone about your bulimia, what factors encouraged you to disclose your bulimia? What factors posed barriers or "got in the way" of disclosing your 
bulimia? Do you have any suggestions for health care providers about helping individuals to disclose or reveal their bulimia?

Written consent was obtained from the various primary care and psychiatric private practices to conduct the study and Institutional Review Board (IRB) was approved by the university. Survey packets attached to a flyer were posted in the five waiting rooms. A cover letter articulating the purpose of the study, identifying the investigators, assuring anonymity, and encouraging participation accompanied the survey as well as information regarding an incentive of $\$ 10.00$ gift certificate to Best Buy Stores for participation. Consent was implied by voluntary completion and submission of the survey. Participants mailed the completed surveys to the researcher with no information related to their identities on the surveys or returned envelopes.

Content analysis was used to analyze the open-ended questions related to facilitators and barriers to disclosure of BN. Krippendorff's method of content analysis was used for this study because of its "descriptive richness" [28, p. 290]. The inductive approach was used to analyze the data since there has not been sufficient knowledge related to disclosure of BN using qualitative methodology. This process incorporates open coding, creating categories and abstraction. Thematic units were chosen for this study because of their descriptive richness. The coded comments totaled nearly 2,000 words: individual comments ranged from one word to 322 words (average 54 words). Data were coded by selecting exact words, passages, or sentences that related to the research question noting unique comments as well as recurrent passages. The second and third author and adviser analyzed and coded each transcribed questionnaire. Each coder independently reviewed, selected, and coded participant responses. The transcripts were discussed line by line and coding among the two coders was reconciled to represent consensus about the meaning of participant comments. Since most information collected related to open ended questions trying to discover underlying themes, the responses became similar very quickly and we found the themes being repeated within the sample. Not surprisingly, most BN women did not feel comfortable with disclosure (discussing their eating disorder) and we were excited to have this sample size.

\section{Results}

Demographics related to the sample are described in Table 1. One interesting finding was the wide variation in age from 20-62; studies of BN usually have a large number of younger women (15 years and up). Unfortunately, since this was a self-reported survey completed at a physician's office or Behavioral Medicine clinic, younger women ( $<18$ years) were excluded. However, the age group used in this study offered a unique glimpse of self-disclosure of BN from a wide range of women not studied as frequently as young women with this disorder (15 to 24 years).

The questions focused specific on self-disclosure, there were five "feelings" identified consistently by the participants: embarrassment, shame, fear, stigma, judgment and labeling. The majority of the participants expressed these feelings and believed they played a significant role in self-disclosure of their disorder.

\subsection{Self-disclosure}

While participants self-disclosed to various individuals including relatives, friends, health providers and therapists, their statements supported the notion that self-disclosure was impacted by people they viewed as a "safety net" in their lives. Important attributes included the ability to trust this particular person, the recognition that this person would not judge or stigmatize them; and the participant felt "safe" in disclosing to this individual. Additionally, some participants opened-up to those who had shared a similar history with this BN. For example, a participant revealed her secret to a friend in college who also suffered from BN. Another disclosed to her mother stating "she had it too."

Participants' comments suggested that individual accountability and responsibility for revealing a history of BN was an important mediator toward self-disclosure. The incentive to disclose was prompted by concerns of health. They wanted to get better. However, how the participant responded to the healthcare provider depended on a connection and/or commit- 
ment to the relationship from the provider. Additionally, the provider's keen insight, awareness and observations of individuals with BN positively impacted participants to feel more comfortable in discussing their illness.

Table 1. Bulimia Survey Demographics

\begin{tabular}{|c|c|c|c|c|c|c|c|}
\hline \multicolumn{8}{|c|}{ Bulimia Survey Demographics } \\
\hline & Question 1 & Question 2 & Question 3 & Question 4 & Question 5 & Question 6 & Question 7 \\
\hline Respondent & Age & Race & Education & Employment & $\begin{array}{l}\text { Age first } \\
\text { aware of BN }\end{array}$ & $\begin{array}{l}\text { Age of time } \\
\text { of Disclosure }\end{array}$ & $\begin{array}{l}\text { To whom did you first } \\
\text { talk to about your } \\
\text { bulimia? }\end{array}$ \\
\hline 1 & 39 & Caucasian & College & Full-time & 30 & 38 & Therapist \\
\hline 3 & 55 & Caucasian & College & No & 20 & 37 & Health Care Provider \\
\hline 4 & 62 & Caucasian & 2 yrs College & Full-time & 24 & 45 & Friend \\
\hline 5 & 59 & Latino & College & Part-time & 52 & 57 & Health Care Provider \\
\hline 6 & 20 & Caucasian & High School & Part-time & 14 & 16 & Friend \\
\hline 7 & 30 & Caucasian & $\begin{array}{l}\text { Graduate } \\
\text { School }\end{array}$ & No & 22 & 22 & Mother \\
\hline 8 & 20 & Latino & College Student & Part-time & 12 & 15 & Friend \\
\hline 9 & 25 & Caucasian & High School & Full-time & 14 & 20 & Friend \\
\hline 10 & 28 & Caucasian & College & Full-time & 12 & 13 & Friend \\
\hline 11 & 62 & Caucasian & $\begin{array}{l}\text { Graduate } \\
\text { School }\end{array}$ & Full-time & 20 & 35 & Health Care Provider \\
\hline 12 & 30 & Caucasian & College & Full-time & 20 & 30 & Friend \\
\hline 13 & 43 & Caucasian & College & Part-time & 40 & 40 & Health Care Provider \\
\hline 14 & 34 & Caucasian & GED & No & 14 & 14 & Sister \\
\hline 15 & 42 & Caucasian & College & Part-time & 16 & 16 & Friend \\
\hline Mean & 39 & & & & 22 & 28 & \\
\hline Median & 34 & & & & 20 & 27 & \\
\hline
\end{tabular}

\subsection{Variable time intervals to self-disclosure}

There was a wide variation in the time that it took respondents to divulge their BN to a medical professional. Most of the participants had either not reported their disorder to their advanced practitioner or it had taken several years before they divulged this information. It had already been mentioned that a trusting relationship was extremely important for a participant to disclose her disorder. But also a crisis could trigger self-disclosure due to illness. For example, one participant discussed a relapse with alcoholism in conjunction with her BN. Illness was seen as a motivator that expedited participants' time line toward self-disclosure.

\subsection{Factors of self-disclosure}

Participants navigated different pathways toward self-disclosure and were grouped into two divisions: voluntary self-disclosure where individuals deliberately sought help and those forced to disclose because they were "found out". Those who voluntarily self-disclosed did so because they yearned to feel well or they became fearful of the health consequences of BN. Some participants even felt a sense of guilt motivating them to disclose. Others felt that by not self-disclosing, they would only hurt themselves in the long-run. Overall, participants' comments illustrated acute awareness of their problem and their desire to achieve improved physical and emotional well-being served as motivators to share their secret. Some participants were forced to disclose their BN usually due to someone else's concern. One participant's friend noticed her weight loss; another participant's friend demanded an explanation when she found her laxatives. 


\subsection{Barriers to self-disclosure}

Not surprisingly, participants feared the reaction of others when contemplating self-disclosure. They also harbored personal feelings about themselves that hindered self-disclosure. Participants expressed a variety of personal emotions citing "embarrassment", "hurt”, "shame”, and "guilt”, all posing barriers to self-disclosure. Others used terms such as "fear”, "worry”, and "tense”, relative to public self-disclosure of BN. The comments noted by two women, "I didn't want to be judge[d]", and "I was scared what people would think", demonstrated that the perceptions of negative opinions or "labeling” by others obstructed their ability to disclose.

It is interesting to note that some participants described the secrecy and allure of the act itself. Some respondents failed to disclose because they lacked the desire to stop. These participants actually feared being exposed. They felt that exposure of their BN would result in being forced to stop the behavior. The act of purging was depicted as "personal time" for one respondent; the woman was in full control of her own actions. This woman felt that the "act" of BN was her special time that she did not wish to share with anyone else. The Seduction of the Act far outweighed her sense of loneliness. The respondent expressed her feelings in these terms:

While I'm in the act, I find it to be a very personal time for me. I don't want to share that time with anyone or anything and not just for the obvious reason of being caught. It's hard to express the exact feeling, but it's like having a secret place only you know about and never ever wanting anyone else knowing of. Sometimes you would like company though, but you know if you invite someone in, your secret place will be exposed.

When respondents were asked how advanced practitioners could help them in self-disclosure of their disorder, several actions by advanced practitioners were noted that would encourage self-disclosure: feeling comfortable, having patience in waiting for the respondent to open-up, developing a connection or relationship with the participant through instilling trust, and demonstrating care and concern for the respondent. Simply listening by the advanced practitioner was a consistent comment made by respondents. Others suggested asking direct questions to patients. Some stated that no one ever asked them if they suffered from BN. Respondents further suggested that relaying the dangers and damage to the body caused by BN might facilitate self-disclosure and that providers' listen for clues as to what the patient is really saying. Participants cautioned providers not to be pompous or present with a stiff demeanor. Viewing the patient as "only a disease" got in the way of self-disclosure, as did focusing on time constraints rather than the "patient as a person". Some participants never disclosed because they were never questioned about their BN. Others stated that providers avoided the topic altogether, prompting the participants to encourage providers to assess for BN.

\section{Study limitations}

There were several limitations to this study. The sample size was small and not diverse. The participants were from one small geographical area. Participants self-selected to participate so findings may not reflect the general population who experience BN. Those who participated may be unusually motivated and forthcoming individuals in their responses to the survey and may be more willing to disclose or seek treatment. The sites that were chosen for collection may have limited the number of younger patients who participated. There was no monitoring of who filled out the survey to maintain confidentiality to any participant, thus who actually filled out the survey was not controlled for by the researchers.

\section{Discussion}

The majority of the younger participants initially disclosed to a friend rather than an advanced practitioner supporting other BN research on self-disclosure which supported findings in various research studies examining this population ${ }^{[12,16]}$. However, older women in this study self-disclosed to an advanced practitioner or therapist rather than a friend citing that they needed help regarding their health care concerns and they could only obtain that help by being honest and open about 
their problem. Our research supported that factors which influenced self-disclosure included personal concern about the detrimental health consequences associated with $\mathrm{BN}^{[12,16,17]}$. APN must become more aware that different strategies and interventions are needed to be considered when helping patient's self-disclose information related to their disorder. However, regardless of the age, a trusting relationship based on caring is essential.

The timeline between the respondent's recognition of their BN and the period before seeking medical care varied greatly in our study ranging from never to many years. This study revealed that delay time from recognition of problem to selfdisclosure was variable and $40 \%$ of the respondents still had not sought medical care. Other research also supported a delayed in the time of self-disclosure, noting that less than one-third of BN women sought medical help; the average delayed time from onset of symptoms to first contact with the health provider was five years ${ }^{[15]}$.

There are many opportunities for the ANP to educate the general public regarding the healthcare issues related to BN. Community service programs and health education to women of ANPs and other health care providers should be made readily available cautioning individuals about the physical dangers of $\mathrm{BN}$ and focusing on preventative strategies. Language should be stated in a manner that does not further stigmatize this disorder so that women hopefully will feel more at ease in disclosing. More nursing research exploring patient support systems and the influence it may or may not have related to early self-disclosure is vital. Studies should also focus on awareness and knowledge of the general public regarding BN allowing for earlier detection of bulimic women by family and friends.

This research demonstrated that BN could be prevalent at any age group, and that many of these patients will never come forth to discuss their disorder. This is especially disturbing since $20 \%$ of patients diagnosed with BN will die within 10 years of onset ${ }^{[64]}$. Much more research is needed from APNs related to interventions and outcomes to understand effective methods to assist patients to open up to their advanced practitioners.

This research supported that barriers to self-disclosure included the respondents' feelings of embarrassment, guilt, worry, fear, shame, feeling labeled and being ridiculed by others which was consistent with other studies ${ }^{[12,15,17,19,29]}$. It is important for ANPs to identify these underlining feelings of low self-worth and assuring their patients that they are not judging them, developing a trusting relationship in which the patients will feel comfortable and accepted for whom they are.

It was clear that purging itself played a role in the women's desire to continue this behavior as the act was described as a seduction of sorts hindering self-disclosure. While feelings of loneliness were evident, there appeared to be a mystical phenomenon behind the actual act of purging. A parallel has been associated with other addictive activities such as smoking, heroin use, over eating, alcohol use, violence, and sexual activity where research has suggested the activity "relieves unbearable tension" ${ }^{[30,31]}$. More research needs to be conducted by ANPs to understand more about this seduction and how to break the cycle.

\section{Conclusion}

The majority of research regarding self-disclosure of BN has been clustered together with other EDs such as AN, binge eating disorders and other eating disorders. It is especially important that future research focus on self-disclosure specifically directed at individuals who suffer from BN. Additionally, despite widespread research exploring various aspects of BN, gaps remain in APNs understanding of this disorder, and it is imperative that self-disclosure delay time be explored to avoid complications and associated morbidity and mortality.

There appears to be a unique mystery behind the act of purging. While women felt a sense of seclusion and yearned for that connection to others, the so called "secret place" or the "secret act" deserve investigation into why some women may find 
the act itself alluring. This area offers a new and exciting direction of research for BN that may result in a better understanding as to why patients do not disclose their disorder.

Despite increased awareness of BN on the part of ANPs, other advanced practitioner providers and the general public, this disorder continues to go unrecognized. Given the epidemiology of BN and the resulting untoward health consequences, early identification is vital for both physical and emotional well-being.

\section{References}

[1] Broussard BB. Women’s experiences of bulimia nervosa. Journal of Advanced Nursing. 2005; 49(1); 43-50. PMid:15610380 http://dx.doi.org/10.1111/j.1365-2648.2004.03262.x

[2] Cummins LH, Lehman J. Eating disorders and body image concerns in Asian-American women: Assessment and treatment from a multicultural feminist perspective. Eating Disorders. 2007; 15(3): 217-230. PMid:17520454 http://dx.doi.org/10.1080/10640260701323474

[3] South Carolina Department of Mental Health. Eating Disorder Statistics. Retrieved on April 2013 from http://www.state.sc.us/dmh/anorexia/statistics,htm

[4] Diagnostic and Statistical Manual of Mental Disorders, Text Revision (DSM-IV-TR). Washington, DC: American Psychiatric Association.

[5] Hudson American Psychiatric Association Work Group on Eating Disorders: Practice guideline for the treatment of patients with eating disorders. 2006; 163(1 Suppl):1:1.

[6] Vitale,E, Lotito,L,Baglie RB. A psychoneuroendocrino-immune approach in the nursing treatment of anorexia and bulimia nervosa. Immunopharmarcology and Immunotoxicology. 2009: 31(1): 39-50. http://dx.doi.org/10.1080/08923970802135955

[7] Grohol JM. (2004, August 17). Eating disorders cost millions of dollars for many U.S. businesses. PR Newswire 2004; Retrieved on August 18, 2013, from http://psychcentral.com/blog/archives/2004/08/17/eating-disorders-cost-millions-of dollars-for-many-us-businesses/

[8] Mond JM, Myers TC, Crosby RD, Hay PJ, Mitchell JE. Bulimic eating disorders in primary care: Hidden morbidity still? Journal of Clinical Psychology Medical Settings. 2009; 15: 56-63. http://dx.doi.org/10.1007/s10880-009-9180-9

[9] Watters E. The Americanization of mental illness. The New York Times. January 10, 2010. Retrieved from http://222.nytimes.com

[10] Dichter JR, Cohen J, Connolly PM. Bulimia nervosa: knowledge, awareness and skill levels among advanced practice nurses. Journal of The American Academy of Nurse Practitioners. 2002; 14(6): 269-275. PMid:12087787 http://dx.doi.org/10.1111/j.1745-7599.2002.tb00124.x

[11] Williams PM, Goodie J, Motsinger CD. Treating eating disorders in primary care. American Family Physician. 2008; 77(2): 187-195. PMid:18246888

[12] Becker AE, Thomas JJ, Franko DL, Herzog DB. Disclosure patterns of eating and weight concerns to clinicians, educational professionals, family, and peers. International Journal of Eating Disorders. 2005; 38(1): 18-23. http://dx.doi.org/10.1002/eat.20141

[13] Troop NA, Allan S, Serpell L, Treasure JL. Shame in women with a history of eating disorders. European Eating Disorders Review. 2008; 16: 480-488. http://dx.doi.org/10.1002/erv.858

[14] VandereyckenW, Van Humbeeck I. Denial and concealment of eating disorders: A retrospective view. European Eating Disorders Review. 2008; 16: 109-114. http://dx.doi.org/10.1002/erv.857

[15] Cachelin FM, Striegel-Moore, RH. Help seeking and barriers to treatment in a community sample of Mexican American and European American women with eating disorders. International Journal of Eating Disorders. 2006; 39: $1544-1561$. PMid:16252278 http://dx.doi.org/10.1002/eat.20213

[16] Evans L, Wertheim EH. An examination of willingness to self-disclose in women with bulimic symptoms considering contest of disclosure and negative affect levels. The International Journal of Eating Disorders. 2002; 31(3): 344-348. PMid:11920998 http://dx.doi.org/10.1002/eat.10020

[17] Hepworth N, Paxton SJ. Pathways to help-seeking in bulimia nervosa and binge eating problems: A concept mapping approach. International Journal of Eating Disorders. 2007; 40: 493-504. PMid:17573682 http://dx.doi.org/10.1002/eat.20402

[18] Mond JM, Hay P, Rodgers B, Owen C. Mental health literacy and eating disorders: What do women with bulimic eating disorders think and know about bulimia nervosa and its treatment? Journal of Mental Health. 2008; 17(6): 565-575, Swan S, Andrews B. The relationship between shame, eating disorders and disclosure in treatment. British Journal of Clinical Psychology. 2003; 42: 367-378. http://dx.doi.org/10.1080/09638230701677787

[19] Swan S, Andrews B. The relationship between shame, eating disorders and disclosure in treatment. British Journal of Clinical Psychology. 2003; 42: 367-378. 
[20] Patching J, Lawler J. Understanding women's experiences of developing an eating disorder and recovering: A life -history approach. Nursing Inquiry. 2009; 16(1): 10-21.

[21] Zerbe KJ. Eating disorders in middle and late life: A neglected problem. Primary Psychiatry. 2003; 10(6): 76-78. PMid:16941624 http://dx.doi.org/10.1002/eat.20306

[22] Johnston O, Fornai G, Cabrini S, Kendrick T. Feasibility and acceptability of screening for eating disorders in primary care. Family Practice Advance Access. 2007: 24(5): 511-517. Mond JM, Myers TC, Crosby RD, Hay PJ, Mitchell JE. Bulimic eating disorders in primary care: Hidden morbidity still? Journal of Clinical Psychology Medical Settings. 2009; 15: 56-63.

[23] Striegel-Moore RH, Perrin N, DeBar L, Wilson GT, Rosselli F, Kraemer HC. Screening for binge eating disorders using the patient health questionnaire in a community sample. International Journal of Eating Disorders. 2010; 43(4): 337-43. http://dx.doi.org/10.1002/eat.20694

[24] Yeh H-W, Tzeng N-S, Lai T-J, Chou K-J. Cognitive behavioral therapy for eating disorders. International Journal for Eating Disorders. 2006; 38(1): 73-77.

[25] Meyer DF. Psychological correlates of help seeking for eating disorder symptoms in female college students. Journal of College Counseling. 2005; 8: 20-30. http://dx.doi.org/10.1002/j.2161-1882.2005.tb00069.x

[26] Mond JM, Hay P, Rodgers B, Owen C. Mental health literacy and eating disorders: What do women with bulimic eating disorders think and know about bulimia nervosa and its treatment? Journal of Mental Health. 2008; 17(6): 565-575. http://dx.doi.org/10.1080/09638230701677787

[27] Budd G. Disordered eating: Young women's search for control and connection. Journal of Child and Adolescent Psychiatric Nursing. 2007; 20(2): 96-106. PMid:17598803 http://dx.doi.org/10.1111/j.1073-6077.2007.00091.x

[28] Krippendorff K. Content analysis: An introduction to its metholdology. Los Angeles: Sage Publications, 2013. PMCid:PMC3696095

[29] Vogel DL, Wade N G, Haake S. Measuring the self-stigma associated with seeking psychological help. Journal of Counseling Psychology. 2006; 53(3): 325-337. http://dx.doi.org/10.1037/0022-0167.53.3.325

[30] McCool JP, Cameron LD, Petrie KJ. Interpretations of smoking in film by older teenagers. Social Science and Medicine. 2003; 56(5): 1023-1032. http://dx.doi.org/10.1016/S0277-9536(02)00096-5

[31] Wurmser, L. Psychoanalytic considerations of the etiology of compulsive drug use. Journal of the American Psychoanalytic Association. 1974; 22: 820-843. http://dx.doi.org/10.1177/000306517402200407 